\title{
The Institute of Nuclear Medicine London
}

\author{
Jamshed Bomanji and Peter J. Ell
}

Founded in 1961 with a first director (Professor J.E.Roberts 1961-1963), it developed under the direction of Professor E S Williams (1963-1985) and matured into international recognition under the director Professor Peter J. Ell (1986-2011). By its 50th anniversary, it already listed over 1000 peer reviewed publications, major Text Books and contributions to teaching. A significant milestone was achieved when the Editor of The Lancet commissioned the INM to edit 6 articles describing the clinical practice of Nuclear Medicine in subsequent 6 weekly issues of this premier medical publication (August 21 to September 25, 1999).

The physiological nature of the radionuclide tracer methodology is already transparent in the contents of the first 1961 INM Handbook for clinicians, highlighting the available procedures (Fig. 6.1). These included topographic surveys of the thyroid, liver, brain, haematological tests, such as red cell and platelet cell survival, plasma volume, vitamin B12 and iron absorption, iron clearance, as well as, inter alia, body composition studies with exchangeable sodium and potassium, extracellular fluid volume and total body water measurements. Thyroid function tests were part of the menu, including the assay of T4, the TSH stimulation test and perchlorate discharge testing.

\footnotetext{
J. Bomanji ( $\varangle)$

Clinical Department, Institute of Nuclear Medicine, UCLH NHS Foundation Trust, 235 Euston Road, London NW1 2BU, UK

P.J. Ell 235 Euston Road, London NW1 2BU, UK

Department of Nuclear Medicine, Institute of Nuclear Medicine, UCLH NHS Foundation Trust, 


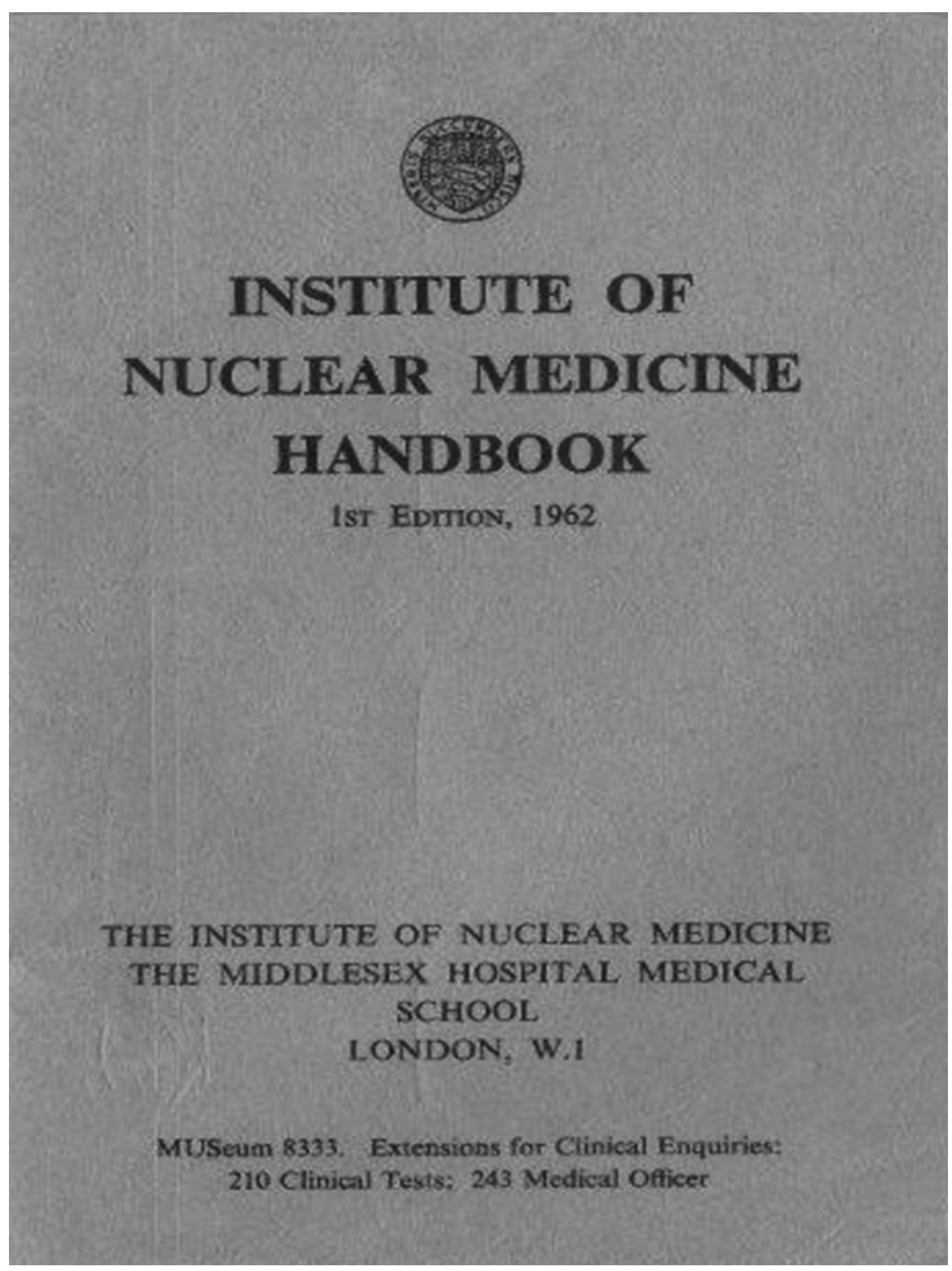

Fig. 6.1 1961 INM Handbook

Leading the speciality in the UK, the INM developed with the Royal Postgraduate Medical School and the Institute of Cancer Research, the first intercollegiate Master of Science Course (MSc) in Nuclear Medicine. This gained wide recognition, and at the INM, some $100 \mathrm{MSc}$ graduates, mostly from overseas, obtained their diploma over the ensuing years. 
The outstanding academic achievement has to be the development of radioimmunoassay and saturation analysis, under Professor Roger P. Ekins (deputy director 1968-1981), changing the world of analytical biochemistry, endocrinology and medicine. A Fellow of the Royal Society, Ekins received the Department of Health's Lifetime Achievement Award in 2011.

Other significant early contributions are highlighted below.

Edward Williams, as a life long mountaineer, investigated electrolyte function, aldosterone excretion and potassium retention at highest altitudes, publishing in Nature, inter alia, in 1961. A. Todd-Pokropek and D. Keeling designed and built in 1969 the first 3 D scanner in Europe, a true precursor of single photon emission tomography (SPET). The subsequent development of single photon emission tomography at the INM became a major success story, the Institute leading the UK in the clinical applications of the $3 \mathrm{D}$ radionuclide imaging technology (with major peer reviewed output emerging from 1979 onwards).

The first UK patient studies with Gallium-67 citrate in 1970 in lymphoma by David Keeling and the development of deconvolution analysis in renography by Keith Britton and Nicholas Brown in 1968/1969, require to be highlighted here.

As novel radionuclide labelled tracers began to enable a transition to be made from mostly anatomical representation of organs (for example altered blood brain barrier imaging with pertechnetate, or liver imaging, even when mediated, for example, by Kupfer cell uptake) towards more pathophysiological meaningful pathway representations, the INM was able to keep at the forefront of what later would became known as molecular imaging. Hence the INM led the imaging with lypophilic tracers such as HMPAO for blood flow studies of the brain (1985), receptor imaging probes such as methoxybenzamide for imaging the D2/D3 dopaminergic system (1990), iomazenil for imaging the benzodiazepine receptor (1997), and investigating, inter alia, probes for the NMDA receptor (2003), for cell proliferation (2003), the 5-HT2A receptor (2006), the sigma-1 receptor (2006), and the somatostatin receptor in 2008 .

A further first for the UK was the INM introduction of X-Ray based dual photon absorptiometry, in late 1988. This completely changed the accuracy and precision of bone mineral density measurements, the technology rapidly diffusing throughout the UK, with the newly established National Osteoporosis Society. In a short period of time, several seminal peer reviewed publications arose from the staff at the INM, such as in BJR 1989, BJR 1990, EJNM 1991.

By 1986, almost $25 \%$ of all diagnostic procedures carried out at the INM involved the investigation of the heart (myocardial perfusion, wall motion, and ventricular ejection). The INM developed pharmacological stress testing with adenosine and dobutamine, with peer reviewed data in BHJ 1989, JACC and AHJ in 1991 and Circulation in 1998. Richard Underwood undertook a landmark study, with one the very few cost benefits studies published in the field of Nuclear Medicine (European Heart Journal 1999). A further first was the use of PETCT and Rb82, combining CT angiography with PET based perfusion, for myocardial studies (Groves 2007) followed by the introduction to the UK of solid state technology and dual radionuclide myocardial perfusion by Simona Ben Haim in 2010 (Fig. 6.2). 
1972

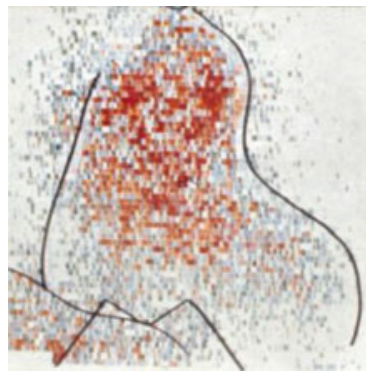

2010

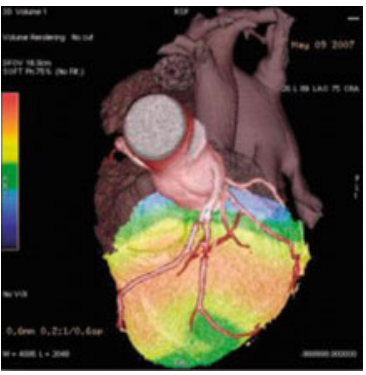

1990

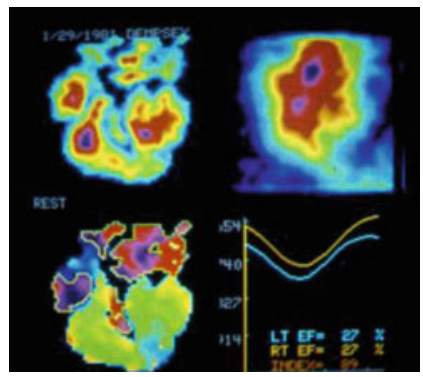

Fig. 6.2 Shows the evolving NM imaging technologies of the heart, from early K-42 studies in the 70s, to phase and amplitude with EF data in the 90s and Rb-52 PETCT in 2010
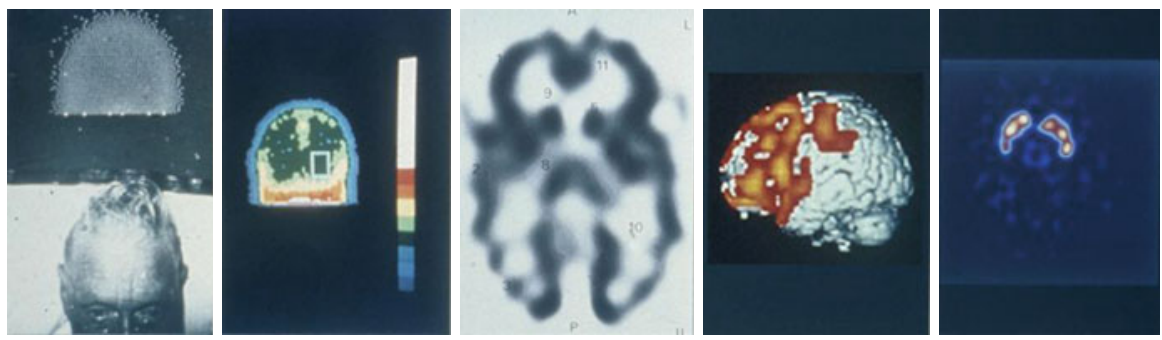

Fig. 6.3 Showing early BBB imaging, cerebral blood flow, MR co-registered benzodiazepine imaging and dopamine transporter imaging

From its early beginnings in the 60's and until the present time, the INM was always committed and involved in the development of imaging probes to study the brain, in its complexity and varied pathologies. Whilst a more detailed description is to be found in another chapter of this anniversary book, it is useful to recall the use of brain blood barrier scanning in the evaluation of patients with subdural haematoma, stroke, space occupying masses, the use of I123 and Tc99m labelled probes for the investigation of refractory temporal epilepsy, the dementias (Pick's and especially Alzheimer type) and the use of dopamine transporter probes for the investigation of essential tremor and Parkinsonian syndromes.(peer reviewed publications in, inter alia, The Lancet 1985, Lancet 1986, Lancet 1989, BMJ 1992 , Lancet 1992 (Fig. 6.3).

From 1998 onwards, a major program in surgical oncology was developed at the INM It was based on a very simple but attractive concept, namely that lymph node progression in several major cancers is predictable and can be investigated when patients present with early disease. So the concept of the sentinel node and its biopsy was investigated in detail by the surgical and nuclear medicine teams (M. Keshtgar, W. Waddington, and P. Ell), with special emphasis of staging patients with early breast carcinoma. This novel technique proved to be extraordinarily effective, sparing invasive axillary surgery in 2 out of 3 patients presenting early with their 
condition. The INM started a major teaching program in the clinical skills lab, over 100 attendees benefited from their exposure to this training program, a Text Book and a CD was published and a substantial contribution to the literature ensued (inter alia, Lancet 1998, Lancet 1999, Lancet Oncology 2002, J. National Cancer Institute 2006, and EJNM 2000, European J. Surgical Oncology 2004).

\subsection{UK Introduction of PETCT and PETMR}

INM was first to introduce these major disruptive technologies to the UK (Ell PJ,von Schulthess GK. PET/CT: a new road map. Eur J Nucl Med Mol Imaging. Jun; 29(6):719-20, 2002) . The first UK patient to benefit from this new development was investigated with PETCT on the 17th of January 2002! PET/CT led to a dramatic increase in the acceptance and utility of the PET clinical programme - in the 3 months of September, October and November 2002, 402 patients were investigated with this unique technology. In a decade, over 100 peer reviewed INM publications were published (Fig. 6.4).

The management of patients with cancer changed, early staging and early treatment response have become paradigms of the clinical usefulness of this approach. As a multimodality imaging investigation, the referral base was rapidly extended to

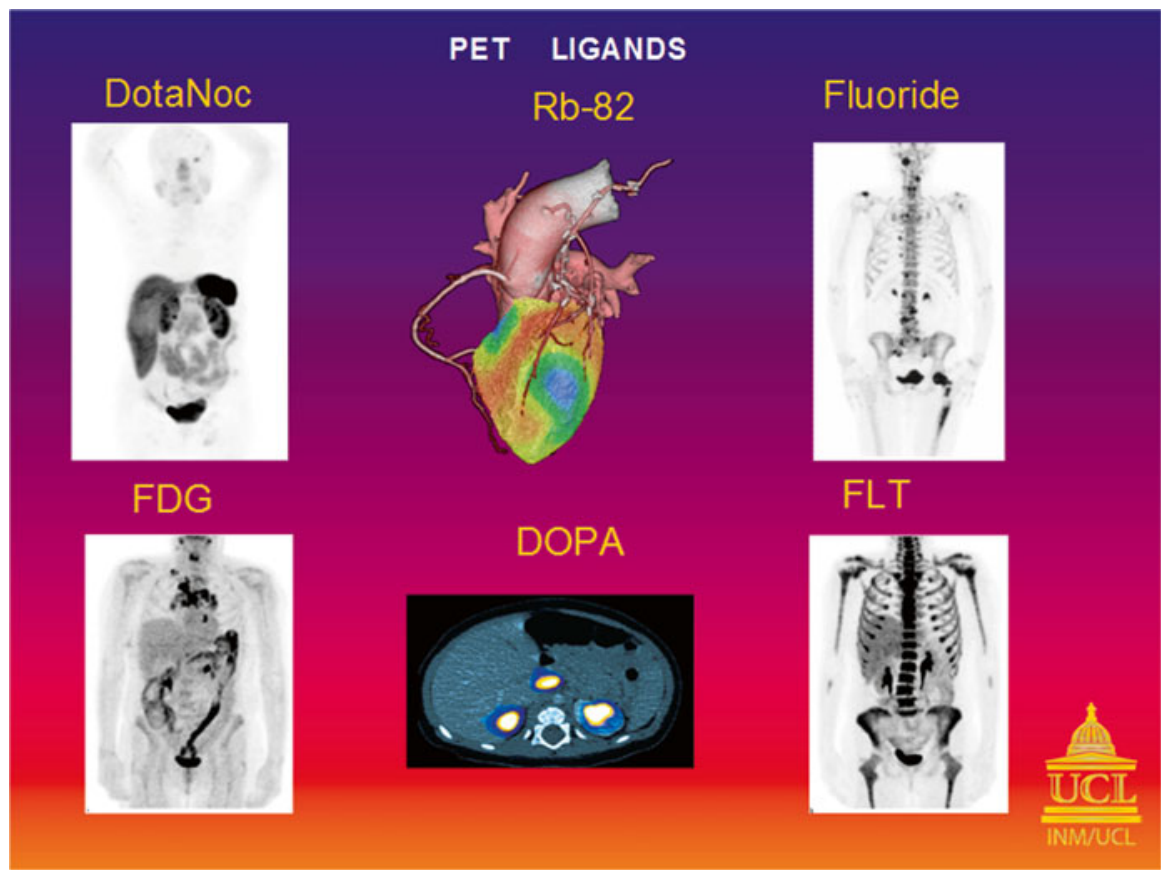

Fig. 6.4 Shows a range of labelled imaging probes which have been investigated at the INM with PETCT 
include the assessment of cardiac function and coronary artery disease, and most recently, with PETMR, the early demonstration of amyloid plaque deposition in patients with cognitive impairment (early MID or developing AD). The Institute introduced PETMR to the UK in April 2012.

\title{
6.2 The Institute of Nuclear Medicine: National and International Impact on Standards, Teaching, Publishing and Organisation
}

\begin{abstract}
Already mentioned above, the INM was a major contributer to an international recognised MSc course in Nuclear Medicine. Edward Williams, graduated in physics and medicine and became the first Chairman of ARSAC, the national body which issues medical certificates for safe practice. He was involved in writing much of the regulations which deliver safe radiation practice. Keshtgar, Waddington and Ell made a significant contribution to surgical standard setting for the practice of sentinel lymph node biopsy, now adopted by the Royal College of Surgeons as best practice. Peter Ell became Editor of the European Journal of Nuclear Medicine from 1988 to 2003, a major publication in the imaging field, raising the standard, profile and impact factor of this publication Keith Britton, whilst Consultant Physician in charge at INM, brought, as Congress President, the joint Congress of two European Societies of Nuclear Medicine to London in 1985. Britton and Ell wrote the new Bye Laws of the newly constituted single European Association of Nuclear Medicine, and were 2 of the 4 co-signatures founding the Association in 1985. Peter Ell became its President from 1994 to 1996. During his tenure, the European School of Nuclear Medicine was established.
\end{abstract}

Open Access This chapter is distributed under the terms of the Creative Commons AttributionNoncommercial 2.5 License (http://creativecommons.org/licenses/by-nc/2.5/) which permits any noncommercial use, distribution, and reproduction in any medium, provided the original author(s) and source are credited.

The images or other third party material in this chapter are included in the work's Creative Commons license, unless indicated otherwise in the credit line; if such material is not included in the work's Creative Commons license and the respective action is not permitted by statutory regulation, users will need to obtain permission from the license holder to duplicate, adapt or reproduce the material.

\section{Selected References}

Ayres PJ, Hurter RC, Williams ES, Rundo J. Aldosterone excretion and potassium retention in subjects living at high altitude. Nature. 1961;191:78-80.

Cullum I, Ell PJ, Ryder J. X-Ray dual photon absorptiometry - a new method for the measurement of bone density. Br J Radiol. 1989;62:587-92.

Ekins RP. The estimation of thyroxine in human plasma by an electrophoretic technique. Clin Chimica Acta. 1960;5:453-9.

Ell PJ, Cullum I, Costa DC. Regional cerebral blood flow mapping with a new Tc-99m labelled compound. Lancet. 1985;II:50-1. 
Groves AM, Speechly-Dick ME, Kayani I, Pugliese F, Endozo R, McEwan J, Menezes LJ, Habib SB, Prvulovich E, Ell PJ. First experience of combined cardiac PET/64-detector CT angiography with invasive angiographic validation. Eur $\mathrm{J}$ Nucl Med Mol Imaging. 2009;36(12):2027-33.

Gunning MG, Agnastopoulos C, Knight CJ, Ppper K, Burman ED, Davies G, Kox KM, Pennell DJ, ELL PJ, Underwood SR. Comparison of thallium-2o1, technetium-99m-tetrofosmin and dobutamine magnetic resonance imaging for identifying hibernating myocardium. Circulation. 1998;98(18):1869-74.

Keeling DH, Todd Pokropek AE. A new approach to brain scanning and Tomographic reconstruction. Proceedings of the second congress of the European Association of Radiology, Amsterdam. Amsterdam: Excerpta Medica; 1971

Keshgar M, ELL PJ. Sentinel lymph node biopsy in breast cancer. Lancet. 1998;352: 1471-2.

Sullivan R, Peppercorn J, Sikora K, Zalcberg J, Meropol NJ, Amir E, Khayat D, Boyle P, Autier P, Tannock IF, Fojo T, Siderov J, Williamson S, Camporesi S, McVie JG, Purushotham AD, Naredi P, Eggermont A, Brennan MF, Steinberg ML, De Ridder M, McCloskey SA, Verellen D, Roberts T, Storme G, Hicks RJ, Ell PJ, Hirsch BR, Carbone DP, Schulman KA, Catchpole P, Taylor D, Geissler J, Brinker NG, Meltzer D, Kerr D, Aapro M. Delivering affordable cancer care in high-income countries. Lancet Oncol. 2011;12(10):933-80. 


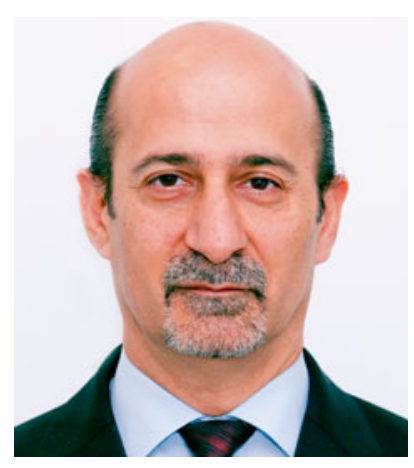

Dr. J Bomanji Dr. J Bomanji completed his graduation in 1980. He did his post-graduation at St Bartholomew's Hospital where he completed his Masters and $\mathrm{PhD}$ in Nuclear Medicine in 1987. He was appointed as Consultant in Nuclear Medicine at St Bartholomew's Hospital in 1990 and then moved to The Middlesex Hospital in 1993, which is now part of the UCLH NHS Foundation Trust. Currently, he is the Clinical Lead and Head of Clinical Department at the Institute of Nuclear Medicine. His main interests are in the diagnostic and therapeutic application of nuclear medicine techniques in oncology, nephrology/urology, cardiology and neurology for benign and malignant disease.

He has contributed and published more than 200 research and clinical papers in peer-reviewed journals, authored numerous book chapters and is the editor of Nuclear Medicine in Oncology. He is assistant editor and advisory editor of various journals in the field of nuclear medicine. 